\title{
Accelerated diastolic dysfunction in premenopausal women with rheumatoid arthritis
}

\author{
Gee Hee Kim ${ }^{1}$ and Yune-Jung Park ${ }^{2^{*}}$ (D)
}

\begin{abstract}
Background: Disturbances of diastolic function precede systolic heart failure and, although clinically silent, represent the earliest sign of cardiac involvement. Diastolic dysfunction (DD) is associated with age, gender (female), and hypertension. However, little is known about the age-specific incidence rates and risk factors for DD in patients with rheumatoid arthritis (RA).

Methods: We used standard two-dimensional/Doppler echocardiography to screen for the presence of diastolic dysfunction in 61 patients with RA and 107 healthy subjects. All participants were premenopausal women with no history of hypertension. DD includes an impaired relaxation with or without increased left ventricular (LV) filling pressures, pseudonormal filling, and restrictive filling based on parameters measured using echocardiography.

Results: The two groups were similar with respect to age $(P=0.269)$. Patients with RA had significantly higher LV mass index, LV filling pressure, and lower E/A velocity than controls. All patients had preserved ejection fraction (EF $\geq 50 \%$. DD was more common in patients with RA at $47 \%$ compared to $26 \%$ in the controls $(P=0.004)$. Women with RA in the 30- to 49-year age range were over 3.5 times more likely to have DD than those of similar age in the control group (OR=3.54; 95\% Cl 1.27 to 9.85). Among patients with RA, high CRP levels were independently associated with DD even after adjustment for cardiovascular risk factors $(P=0.009)$.

Conclusions: In premenopausal women with RA, DD is much more common and the age of onset is reduced. Early screening of myocardial function may provide an opportunity for preventing future cardiovascular disease.
\end{abstract}

Keywords: Diastolic dysfunction, Rheumatoid arthritis, Premenopausal women

\section{Introduction}

As compared to the general population, patients with rheumatoid arthritis (RA) experience a higher incidence of heart failure (HF) [1]. HF is a major risk factor for mortality in RA and is associated with cardiovascular deaths in patients with RA [2]. Various studies have shown that subclinical left ventricular

\footnotetext{
* Correspondence: jwas@catholic.ac.kr

${ }^{2}$ Division of Rheumatology, Department of Internal Medicine, St. Vincent's Hospital, College of Medicine, The Catholic University of Korea, Suwon, Korea Full list of author information is available at the end of the article
}

(LV) diastolic dysfunction predicts future development of clinical HF [3, 4].

Diastolic dysfunction refers to abnormal mechanical properties of the myocardium and includes impaired LV diastolic distensibility, abnormal filling, and slow or delayed relaxation [5]. According to a recent systematic review, diastolic dysfunction affects approximately $36 \%$ of the population older than 60 years [6] and is closely associated with several cardiovascular risk factors, including hypertension, obesity, and diabetes [7, 8]. In the Olmsted County Heart Function Study (a populationbased cohort), 4 years of follow-up revealed that LV 
diastolic dysfunction is highly prevalent, tends to worsen over time, and is associated with advancing age and development of HF during 6 years of subsequent follow-up [9].

Previous reports have demonstrated that the prevalence of diastolic dysfunction is increased in patients with RA [10]. Although inflammation such as tumor necrosis factor-alpha (TNF- $\alpha$ ) and interleukin-6 (IL-6) levels, cardiotoxic medication, and RA disease itself have been thought to be the risk factors for the development of diastolic impairment, the precise mechanisms involved in increased cardiovascular disease (CVD) risk are various and remain elusive [11]. Moreover, few studies have been conducted specifically investigating age, which is one of the strongest risk factors. In this study, we investigate age-related prevalence and risk factors of diastolic dysfunction in RA patients.

\section{Methods}

\section{Patients}

We included patients age $\geq 18$ years with adult-onset RA ( $n=61)$, classified by the American College of Rheumatology (ACR)/European League Against Rheumatism (EULAR) 2010 criteria [12] who had received treatment for at least 6 consecutive months. The status of menopause was confirmed through the questionnaire and premenopausal women were enrolled. Age- and sexmatched individuals $(n=107)$ who underwent health checkup during the same period were included as a control group.

All subjects underwent a clinical and laboratory evaluation, and the following information was collected: traditional CVD risk factors, such as blood pressure, dyslipidemia, diabetes mellitus, smoking status, and body mass index (BMI). The status of cigarette smoking and menopause were elicited by a self-administered questionnaire and current smoking was defined as any smoking within the past year. Subjects with any of the following conditions were excluded: preexisting overt coronary artery disease, transient ischemic attack, stroke, congestive heart failure, hypertension, renal failure (defined as a serum creatinine level $>3.0 \mathrm{mg} / \mathrm{dl}$ ), active infection, and pregnancy. Among the CVD risk factors hypertension was excluded because hypertensive patients often already have myocardial changes and the effects of antihypertensive drugs on diastolic function can be different.

Laboratory parameters included complete blood count, blood levels of glucose, creatinine, electrolytes, total cholesterol, low-density lipoprotein cholesterol, highdensity lipoprotein (HDL) cholesterol, triglycerides, erythrocyte sedimentation rate (ESR), and C-reactive protein (CRP). Characteristics of disease duration and the presence of extra-articular manifestations, rheumatoid factor (RF), and anti-cyclic citrullinated peptide
(Anti-CCP) antibody were recorded for patients with RA. Information about the use of medications including prednisolone, non-steroidal anti-inflammatory drugs (NSAI Ds), methotrexate, leflunomide, hydroxychloroquine, sulfasalazine, TNF inhibitors, and statin was retrieved from medical records. Disease activity was evaluated by using the 28-joint assessment (DAS28) score [13]. All subjects gave written consent before entering the study, which was approved by the institutional review board of the Catholic University of Korea (No. VC14OISI0185)

\section{Transthoracic Doppler echocardiography}

Two-dimensional, M-mode, pulsed Doppler and tissue Doppler echocardiography were performed using a Vivid Seven ultrasound machine (GE Medical Systems, Horten, Norway) with a $2.5-\mathrm{MHz}$ transducer. Standard twodimensional measurements (LV diastolic and systolic dimension, ventricular septum and posterior wall thickness, and left atrial volume) were obtained as recommended by the American Society of Echocardiography [14]. From the apical window, a 1- to 2-mm pulsed Doppler sample volume was placed at the mitral valve tip, and mitral flow velocities from five to 10 cardiac cycles were recorded. The mitral inflow velocities were traced and the following variables were obtained: peak velocity of early diastolic mitral inflow $(E)$, late diastolic mitral inflow (A), and deceleration time of the $\mathrm{E}$ velocity [15]. Stroke volume was measured from the LV outflow tract diameter and the pulse-wave Doppler signal. Mitral annular velocities were measured by Doppler tissue imaging using the pulsed-wave mode. The filter was set to exclude high-frequency signals, and the Nyquist limit was adjusted to a range of 15 to $20 \mathrm{~cm} / \mathrm{s}$. Gain and sample volume were minimized to allow a clear tissue signal with minimal background noise. Early diastolic mitral annular (Em), late diastolic (Am), and systolic velocities $(\mathrm{Sm})$ of the mitral annulus were measured from the apical 4-chamber view, with a 2- to 5$\mathrm{mm}$ sample volume placed at the septal corner of the mitral annulus. Diastolic dysfunction is categorized by Doppler echocardiographic findings into the following progression: grade I defined as impaired relaxation with or without mild evidence of increased filling pressures, grade II defined as impaired relaxation associated with moderate elevation of filling pressures or pseudonormal filling, and grade III defined as advanced reduction in compliance restrictive filling [16]. In this study, diastolic dysfunction was categorized as grade I, grade II, or grade III.

\section{Statistical analysis}

Variables with a normal distribution are presented as the mean \pm SD. Differences between the mean values were examined by Student's $t$-test. Variables showing a non- 
normal distribution were expressed as the median and interquartile range (IQR). Nonparametric data were compared between groups using the Mann-Whitney $U$ test. For categorical data, the difference in prevalence was evaluated by the chi-square test first and then if there were any warnings Fisher's two-tailed exact test was performed. Cumulative probability plots were used to display the diastolic dysfunction, which was based on age in patients with RA.

Multivariate regression analysis was performed to investigate risk factors associated with the diastolic dysfunction in patients with RA. Multivariate models included all covariates with associations from univariate analysis with a $P$-value $\leq 0.20$ and potential confounding factors known to influence diastolic dysfunction (Supplementary Table 1). $P$ values $<0.05$ were considered significant. Data analyses were performed using R (http:// www.R-project.org and web-r.org) software.

\section{Results}

\section{Characteristics of study population}

The baseline characteristics of the 61 RA patients and 107 healthy controls are shown in Table 1. The mean age was $48.1 \pm 7.9$ years in RA patients and $47.3 \pm 9.4$ years in healthy subjects $(P=0.269)$. The mean body mass index was lower in RA patients than in non-RA controls but there were no significant differences found in lipid profile, creatinine levels, or percentage of patients with diabetes mellitus between the two groups. RA patients had higher diastolic blood pressure and HDL cholesterol levels than controls $(P=0.011$ and $P<0.001$, respectively). In RA patients, the median disease duration was 6.9 years, and the median DAS28 score was 3.0. Forty-five patients (73.8\%) were positive for RF and 54 patients (88.5\%) were positive for anti-CCP antibodies. Forty-four patients $(72.1 \%)$ were taking weekly methotrexate, 22 (36.1\%) were on leflunomide, and $16(26.2 \%)$ were on sulfasalazine. Forty-two patients $(68.9 \%)$ were treated with low-dose prednisolone ( $\leq 7.5 \mathrm{mg} /$ day $)$.

\section{Prevalence of diastolic dysfunction and echocardiography findings}

Table 2 shows echocardiography findings in patients with RA. The incidence of diastolic dysfunction was increased in patients with RA (odds ratio 2.18 , 95\% confidence interval (CI)1.13-4.20, $P=0.020$ ). There were significant differences in LVEDD, LV mass index, E/Em, $\mathrm{E}$ and $\mathrm{A}$ wave velocity, $\mathrm{Sm}$, and Em between the two groups.

\section{Risk factors associated with diastolic dysfunction in RA patients}

Univariate and multivariate regression analyses were applied to identify the risk factors for diastolic dysfunction in patients with RA. In multivariate logistic regression analysis, older age $(P=0.035)$ and CRP levels $(P=$ $0.022)$ were independently associated with diastolic dysfunction in the RA patients (Supplementary Table 1). Elevated serum CRP levels remained significant after adjustment for age $(P=0.009)$ (Table 3$)$.

Table 1 Baseline characteristics of the study participants

\begin{tabular}{|c|c|c|c|}
\hline & RA patients ( $n=61)$ & Controls $(n=107)$ & $P$ value $^{\dagger}$ \\
\hline Age, years & $48.1 \pm 7.9$ & $47.3 \pm 9.4$ & 0.269 \\
\hline Duration of disease, years & $6[3-12]$ & NA & NA \\
\hline Current smoker, $n(\%)$ & $5(8.2)$ & $2(1.9)$ & $0.100^{\ddagger}$ \\
\hline \multicolumn{4}{|l|}{ Blood pressure, $\mathrm{mmHg}$} \\
\hline Systolic & $125.7 \pm 18.1$ & $124.4 \pm 16.9$ & 0.075 \\
\hline Diastolic & $81.4 \pm 11.2$ & $78.8 \pm 18.1$ & 0.011 \\
\hline Diabetes mellitus, $n(\%)$ & $1(0.02)$ & $4(0.04)$ & $0.654^{\ddagger}$ \\
\hline Body mass index, $\mathrm{kg} / \mathrm{m}^{2}$ & $22.8 \pm 3.5$ & $23.6 \pm 3.2$ & 0.315 \\
\hline Creatinine, $\mathrm{mg} / \mathrm{dl}$ & $0.62 \pm 0.11$ & $0.69 \pm 0.11$ & 0.121 \\
\hline \multicolumn{4}{|l|}{ Cholesterol, mg/dl } \\
\hline Total & $185.2 \pm 31.9$ & $193.1 \pm 44.0$ & 0.355 \\
\hline High-density lipoprotein & $57.9 \pm 16.4$ & $46.6 \pm 12.3$ & $<0.001$ \\
\hline Low-density lipoprotein & $94.9 \pm 25.4$ & $113.9 \pm 35.5$ & 0.068 \\
\hline Triglyceride, mg/dl & $93.0 \pm 48.8$ & $117.3 \pm 83.4$ & 0.425 \\
\hline Statin, $n(\%)$ & $7(11.5)$ & $0(0)$ & $<0.001^{\ddagger}$ \\
\hline
\end{tabular}

Data are presented as mean \pm standard deviation, median [interquartile range], or number (percentage) as appropriate

NA not applicable

'Unless otherwise noted, two-sample $t$ test was used

${ }^{\ddagger}$ Fisher's two-tailed exact test was used 
Table 2 Comparison of echocardiography findings between patients with rheumatoid arthritis (RA) and control subjects

\begin{tabular}{|c|c|c|c|}
\hline Variables & RA patients $(n=61)$ & Controls $(n=107)$ & $P$ value \\
\hline LVEDD, $\mathrm{mm}$ & $46(44.3-49.3)$ & $45.0(42.6-47.0)$ & 0.033 \\
\hline LVESD, mm & $29.1(27.2-31.4)$ & $28.1(26.0-30.0)$ & 0.131 \\
\hline $\mathrm{LV}$ mass index, $\mathrm{g} / \mathrm{m}^{2}$ & $151.7(128.2-173.1)$ & $140(119-165)$ & 0.043 \\
\hline LV ejection fraction, \% & $64(61.7-65.8)$ & $64.6(62.0-67.3)$ & 0.349 \\
\hline LV filling pressure, $\mathrm{E} / \mathrm{Em}$ & $9.4(8.5-10.1)$ & $9.0(8.7-10.0)$ & 0.036 \\
\hline Transmitral E wave velocity, $\mathrm{cm} / \mathrm{s}$ & $68.5(55.3-79.9)$ & $72.4(64.0-82.8)$ & 0.008 \\
\hline Transmitral A wave velocity, $\mathrm{cm} / \mathrm{s}$ & $70.0(57.0-81.8)$ & $65.8(57.0-77.0)$ & 0.045 \\
\hline Transmitral E wave / A wave verocity & $0.93(0.77-1.28)$ & $1.15(0.85-1.32)$ & 0.003 \\
\hline Systolic tissue velocity $(\mathrm{Sm}), \mathrm{cm} / \mathrm{s}$ & $6.9(6.1-8.0)$ & $8.0(7.0-9.0)$ & $<0.001$ \\
\hline Early diastolic tissue velocity $(\mathrm{Em}), \mathrm{cm} / \mathrm{s}$ & $7.7(6.0-10.4)$ & $9.8(7.4-11.9)$ & 0.001 \\
\hline Late diastolic tissue velocity $(\mathrm{Am}), \mathrm{cm} / \mathrm{s}$ & $8.7(7.2-9.6)$ & $9.3(8.0-10.5)$ & 0.105 \\
\hline Transmitral E wave deceleration time, ms & $201(175.7-227.3)$ & $190.4(163.7-214.8)$ & 0.047 \\
\hline
\end{tabular}

Data are presented as median (IQR). $L V E D D$, left ventricular end diastolic dysfunction; $L V E S D$, left ventricular end systolic dysfunction; $E$, transmitral $E$ wave velocity; $A$, transmitral A wave velocity; $S m$, systolic tissue velocity; $E m$, early diastolic tissue velocity; $A m$, late diastolic tissue velocity; $D T$, transmitral $E$ wave deceleration time

The predicted probability of diastolic dysfunction increased with increasing age in both groups. However, although the probability of diastolic dysfunction was not different between the elderly group, RA patients under 50 years of age showed an increased risk of diastolic dysfunction (Fig. 1). In particular, women with RA in the 30- to 49-year age group were over 3.5 times more likely to have diastolic dysfunction than those of similar age in the control group (OR=3.54; 95\% CI 1.27 to 9.85).

\section{Discussion}

Patients with RA have a high CVD mortality rate and heart failure is a major contributing factor to CVD. An earlier study showed that patients with RA had twice the risk for development of heart failure as control subjects [1]. Subclinical diastolic dysfunction is known to be a major antecedent risk factor for future development of symptomatic heart failure [17]. In this respect, it is important to investigate diastolic dysfunction in RA patients who are asymptomatic for cardiovascular disease. This study demonstrated that the prevalence of diastolic dysfunction in patients with RA was increased in premenopausal women, and this was associated with inflammation.

Clinical studies have found advanced age, hypertension, and women are associated with increased diastolic dysfunction. Most of the studies have been conducted on old-age patients. In particular, the risk of diastolic dysfunction increases sharply in postmenopausal women. It is known that the protective effect of estrogen against hypertension and ventricular remodeling decreases after menopause [18]. This suggests that it is necessary to investigate separately women by age, since the disease risk varies from menopause. Regarding hypertension, hypertension itself does not only significantly affect the stiffness of blood vessels, but it is also one of the strongest risk factors for diastolic dysfunction. The presence of hypertension implies that structural changes in the heart have already begun. For this reason, we narrowed the inclusion criteria and compared with the general population whether RA affects heart function in premenopausal women without a history of cardiovascular disease.

Comparison of the incidence of diastolic dysfunction is illustrated in Fig. 1. The significant influence that age has on the development of diastolic dysfunction is well known [17]. This study also showed that the predicted probability of diastolic dysfunction increased with age in both groups. Interestingly, the control group had an "Sshaped" pattern showing a rapid increase from the mid40 s, whereas the RA patients showed an almost linear increase from the 30s. RA patients aged 30-50 already have a risk of developing diastolic dysfunction comparable to control subjects in their 60s. This indicates that the risk of diastolic dysfunction in RA patients is accelerated, which is in line with the observation that patients with RA over the age of 60 experience a significantly higher incidence of CHF compared to those without [1]. This increased risk of diastolic dysfunction at a younger age is undoubtedly one of the reasons contributing to heart failure at an older age.

Obesity and dyslipidemia are recognized as important risk factors for diastolic dysfunction [17]. Obesity is associated with ventricular remodeling, which may normalize wall stress while increasing stroke volume to match metabolic demand [19]. A relationship between left ventricle dysfunction and serum lipid levels has also been reported [20]. However, as shown in Table 1, the 
Table 3 Characteristics of patients with rheumatoid arthritis, according to the presence or absence of diastolic dysfunction

\begin{tabular}{|c|c|c|c|c|c|}
\hline \multirow[t]{2}{*}{ Characteristics } & \multicolumn{2}{|c|}{ Diastolic dysfunction } & \multirow{2}{*}{$\begin{array}{l}P \text { - } \\
\text { value }^{\dagger}\end{array}$} & \multirow{2}{*}{$\begin{array}{l}\text { Adjusted for age } \\
\text { Odds ratio }{ }^{\ddagger}(95 \% \mathrm{Cl})\end{array}$} & \multirow{2}{*}{$\begin{array}{l}P \text { - } \\
\text { value }^{\ddagger}\end{array}$} \\
\hline & Presence $(n=28)$ & Absence $(n=33)$ & & & \\
\hline Age, years & $50.0[48.5-53.0]$ & $48.0[41.0-51.0]$ & 0.025 & NA & NA \\
\hline Disease duration, years & $6.5[2.0-8.5]$ & $6.0[3.0-11.0]$ & 0.303 & $0.998(0.916-1.086)$ & 0.957 \\
\hline Current smoker, $n(\%)$ & $1(3.6)$ & $4(12.1)$ & $0.363^{5}$ & $0.286(0.040-2.037)$ & 0.211 \\
\hline \multicolumn{6}{|l|}{ Blood pressure, mmHg } \\
\hline Systolic & 122.0 [117.0-135.5] & 125.0 [112.0-131.0] & 0.739 & $0.979(0.931-1.029)$ & 0.406 \\
\hline Diastolic & $80.0[75.0-89.0]$ & $80.0[72.0-86.0]$ & 0.249 & $1.029(0.962-1.101)$ & 0.407 \\
\hline Diabetes mellitus, n (\%) & $0(0.0)$ & $1(3.0)$ & $0.999^{/}$ & $0.000(0.000-0.000)$ & 0.999 \\
\hline $\mathrm{BMI}, \mathrm{kg} / \mathrm{m}^{2}$ & $22.9 \pm 3.2$ & $22.9 \pm 3.4$ & $0.971^{\int J}$ & $0.918(0.767-1.099)$ & 0.350 \\
\hline Creatinine, mg/dl & $0.66 \pm 0.12$ & $0.63 \pm 0.10$ & $0.464^{\int J}$ & $1.100(0.007-1.712)$ & 0.171 \\
\hline \multicolumn{6}{|l|}{ Cholesterol, mg/dl } \\
\hline Total & $185.5 \pm 37.5$ & $182.1 \pm 28.6$ & $0.706^{\int 5}$ & $1.006(0.989-1.024)$ & 0.490 \\
\hline $\mathrm{HDL}$ & $48.0[40.0-65.0]$ & $53.0[45.0-64.5]$ & 0.291 & $1.004(0.970-1.040)$ & 0.808 \\
\hline LDL & $116.2[85.0-126.4]$ & 106.2[88.0-121.7] & 0.468 & $0.959(0.899-1.023)$ & 0.200 \\
\hline Triglyceride, mg/dl & $94.0[59.0-139.0]$ & $90.5[53.5-109.0]$ & 0.373 & $0.999(0.987-1.010)$ & 0.816 \\
\hline ESR, mm/hour & 24.5 [13.5-48.5] & $24.0[14.0-39.0]$ & 0.772 & $1.002(0.974-1.030)$ & 0.899 \\
\hline CRP, mg/dl & $0.9[0.1-1.3]$ & $0.2[0.1-0.5]$ & 0.027 & $2.077(1.204-3.585)$ & 0.009 \\
\hline $\mathrm{RF}, n(\%){ }^{\natural}$ & $21(75.0)$ & $24(72.7)$ & 0.999 & $0.999(0.995-1.002)$ & 0.471 \\
\hline Anti-CCP, $n(\%)^{n}$ & $26(92.6)$ & $28(84.8)$ & $0.437^{5}$ & $1.920(0.483-7.626)$ & 0.354 \\
\hline DAS28 & $3.0 \pm 0.7$ & $3.0 \pm 1.0$ & $0.850^{\int J}$ & $0.916(0.209-4.016)$ & 0.907 \\
\hline Prednisolone, $n$ (\%) & $19(67.9)$ & $23(70.0)$ & $0.953^{\jmath}$ & $0.628(0.196-2.009)$ & 0.433 \\
\hline Methotrexate, $n(\%)$ & $20(71.4)$ & $24(72.7)$ & 0.999 & $1.228(0.386-3.911)$ & 0.728 \\
\hline Hydroxychloroquine, $n$ (\%) & $18(64.3)$ & $17(51.5)$ & $0.436^{\jmath}$ & $1.361(0.464-3.991)$ & 0.574 \\
\hline Sulfasalazine, $n(\%)$ & $9(31.1)$ & $7(21.2)$ & $0.390^{\prime}$ & $0.344(0.033-3.557)$ & 0.371 \\
\hline Leflunomide, $n$ (\%) & $9(32.1)$ & $13(39.4)$ & $0.602^{\jmath}$ & $0.479(0.151-1.517)$ & 0.211 \\
\hline TNF inhibitors, $n$ (\%)a & $3(10.7)$ & $5(15.2)$ & $0.715^{\jmath}$ & $0.851(0.173-4.193)$ & 0.842 \\
\hline Statin, $n(\%)$ & $5(17.9)$ & $2(6.1)$ & $0.231^{5}$ & $1.992(0.379-9.750)$ & 0.430 \\
\hline NSAIDs, $n(\%)$ & $19(67.9)$ & $26(78.8)$ & $0.391^{\jmath}$ & $0.470(0.142-1.544)$ & 0.216 \\
\hline
\end{tabular}

Data are presented as mean \pm standard deviation, median [interquartile range], or number (percentage) as appropriate. $C l$ confidence interval, $N A$ not applicable, $B M I$ body mass index, $H D L$ high-density lipoprotein, $L D L$ low-density lipoprotein, $E S R$ erythrocyte sedimentation rate, $C R P C$-reactive protein, $R F$ rheumatoid factor, Anti-CCP antibody anti-cyclic citrullinated peptide antibody, DAS28 Disease Activity Score in 28 joints TNF tumor necrosis factor, NSAIDs non-steroidal anti-inflammatory drugs

${ }^{\dagger}$ Unless otherwise noted, Mann-Whitney $U$ test was used

${ }^{\ddagger}$ Logistic regression was used to obtain age-adjusted odds ratios for the presence of diastolic dysfunction

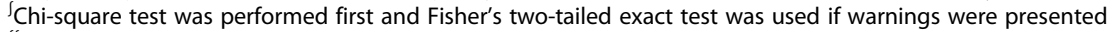

$\iint_{\text {Two-sample } t \text { test was used }}$

"Indicated antibody positivity

BMI of RA patients was lower than that of the control population. In addition, although seven more RA patients were taking statins, the patient group showed a more favorable lipid profile than controls. These observations suggest that the increased risk is not explained by traditional cardiovascular risk factors.

A recent systematic review found a consistent association between diastolic dysfunction and the risk of cardiovascular events and death in community-based populations with different risk factors. As well, individuals with diastolic dysfunction showed a 3.53-fold higher risk of cardiac events or death and a 3.13-fold increased risk of mortality [21]. A meta-analysis found there is an increased prevalence of diastolic dysfunction in RA patients. In this study, the prevalence of diastolic dysfunction, LV mass index, and LV filling pressure were higher in RA patients than in the control group. However, systolic tissue velocity was decreased for these patients. Systolic tissue velocity is an early marker of myocardium contraction.

In this study, serum CRP levels were significantly associated with the risk of diastolic dysfunction in RA and this association remained after adjustment for age and other factors. Inflammation promotes endothelial 


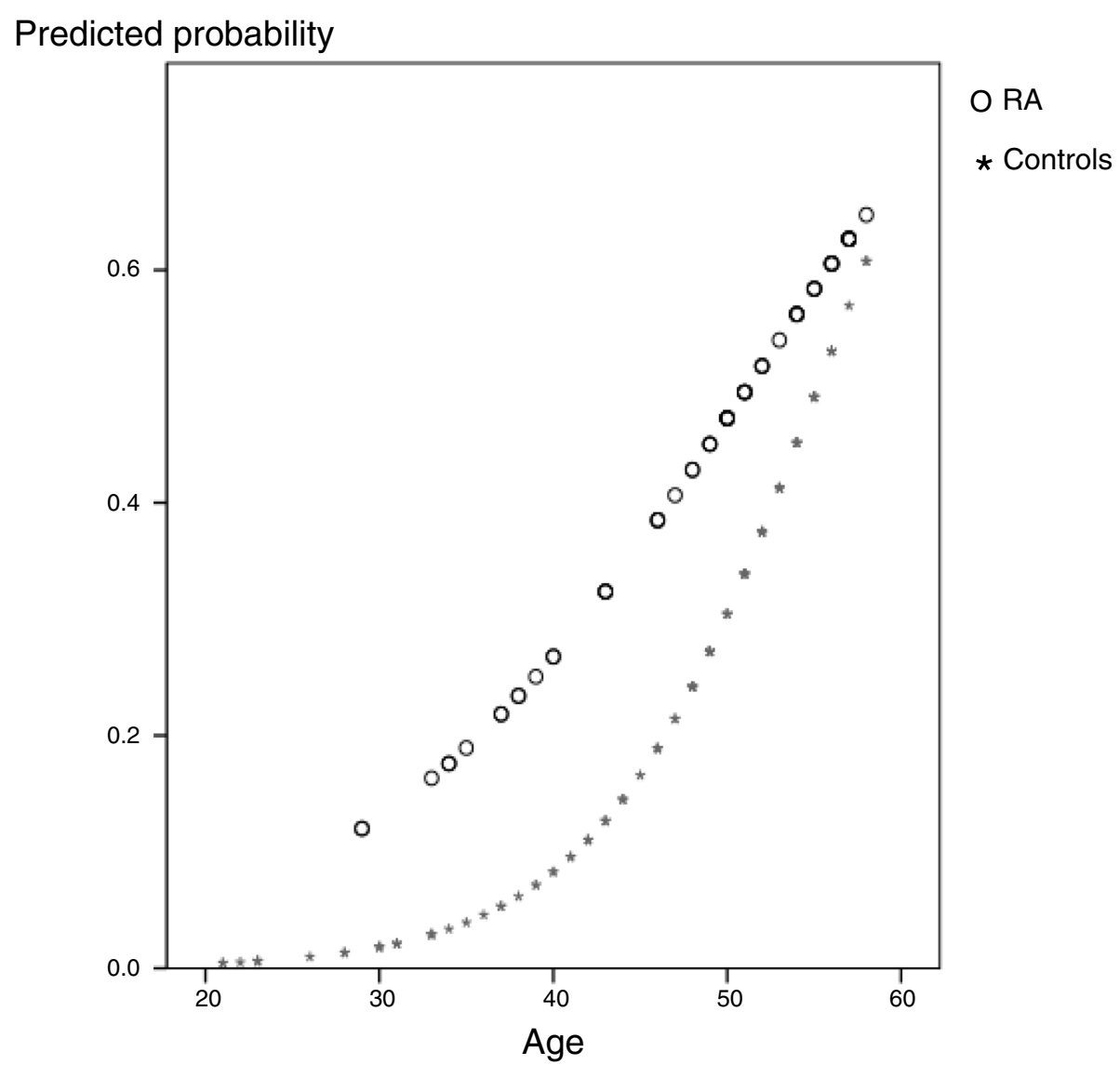

Fig. 1 Predicted probability plot of diastolic dysfunction according to age in the study group: patients with rheumatoid arthritis (RA) (O) and controls $(*)$

dysfunction, myocardial leukocyte infiltration, and oxidative stress [22]. In vitro studies have also revealed that inflammation is involved in cardiac remodeling, resulting in diastolic dysfunction. Indeed, HF patients have high levels of inflammatory cytokines such as TNF- $\alpha$, IL-6, and IL-1ß. These proinflammatory cytokines are correlated with a deterioration of functional and cardiac performance as well as prognostic markers of HF [23]. Furthermore, another study demonstrated increased inflammatory cytokines and diastolic heart failure in patients with RA [10]. Schwartz reported histopathological features such as non-specific myocarditis, myocardial granulomatous lesions, secondary amyloidosis, and diffuse fibrosis in RA [24]. Taken together, the data suggest that inflammation leads to myocardial dysfunction in RA.

Several studies have reported a significant inverse relationship between the E/A ratio and the disease duration $[10,25,26]$. However, the clinical relevance of diastolic dysfunction and its possible relationship to disease duration has not been yet clarified. The study by Montecucco et al. [27] found no association between diastolic dysfunction and disease duration. In this study, we also could not find a significant association between these two variables. Disease duration is a comprehensive variable that implies the accumulation of time and chronic inflammation. But it also includes the period of wellcontrolled inflammation. Furthermore, it is difficult to estimate the disease duration accurately because the disease duration is calculated according to the patient's memory and hospital visit time. This aspect may seem to lead to inconsistent results.

This study has several limitations. First, it did not include patients with hypertension. In the process of studying the prevalence of diastolic heart failure in asymptomatic patients, the age of the enrolled subjects was relatively young. There were very few patients with hypertension, and therefore not enough data for statistical analysis. In the future, we plan to conduct studies in which hypertension patients are stratified and analyzed. Second, this study was conducted in women. According to epidemiological data, the prevalence of RA varies depending on both age and gender. In premenopausal women, the difference in incidence ratio by gender is up to 4.8 times, but for those over 60 it is less than doubled to 1.8. The reason for this distribution is 
not yet fully explained, but clearly, there are differences between women and men, and consequently, caution should be exercised in generalizing across different RA patients.

In summary, premenopausal RA women have a threefold increased risk of diastolic dysfunction compared to control subjects. Inflammation was related to subclinical myocardial involvement. This study provides evidence in premenopausal RA women that early screening of myocardial function may provide an opportunity for preventing future cardiovascular disease.

\section{Abbreviations}

Anti-CCP: Anti-cyclic citrullinated peptide; BMI: Body mass index; CVD: Cardiovascular disease; Cl: Confidence interval; CRP: C-reactive protein; DD: Diastolic dysfunction; DAS28: Disease Activity Score 28 Joints; ESR: Erythrocyte sedimentation rate; HF: Heart failure; HDL: High-density lipoprotein; IL: Interleukin; LV: Left ventricular; NSAIDs: Non-steroidal antiinflammatory drugs; RA: Rheumatoid arthritis; RF: Rheumatoid factor; SD: Standard deviation; TNF-a: Tumor necrosis factor-alpha

\section{Supplementary Information}

The online version contains supplementary material available at https://doi. org/10.1186/s13075-021-02629-1.

Additional file 1:. Supplementary Table 1. Multivariate logistic regression analysis

\section{Acknowledgements}

We thank all medical staff at our institutions participating in this study for providing the data.

\section{Authors' contributions}

YJP was responsible for the conception and design. GHK and YJP contributed to the data extraction and interpretation. YJP contributed to the design and conduction of statistical analysis. GHK and YJP prepared the manuscript. GHK and YJP supervised the manuscript. The authors read and approved the final manuscript.

\section{Funding}

Not applicable.

\section{Availability of data and materials}

The datasets used and/or analyzed in the current study are available from the corresponding author on reasonable request.

\section{Declarations}

\section{Ethics approval and consent to participate}

The current analysis was approved by the Ethics Committees of the institutional review board of the Catholic University of Korea (No. VC14OISI0185). All included patients have signed an informed consent to participate in the data collection and to data publication.

\section{Consent for publication}

All subjects

\section{Competing interests}

The authors have no financial conflict of interest.

\section{Author details}

${ }^{1}$ Division of Cardiology, Department of Internal Medicine, St. Vincent's Hospital, College of Medicine, The Catholic University of Korea, Suwon, Korea. ${ }^{2}$ Division of Rheumatology, Department of Internal Medicine, St. Vincent's Hospital, College of Medicine, The Catholic University of Korea, Suwon, Korea.
Received: 21 June 2021 Accepted: 12 September 2021

Published online: 24 September 2021

\section{References}

1. Nicola PJ, Maradit-Kremers H, Roger VL, Jacobsen SJ, Crowson CS, Ballman $\mathrm{KV}$, et al. The risk of congestive heart failure in rheumatoid arthritis: a population-based study over 46 years. Arthritis Rheum. 2005;52(2):412-20. https://doi.org/10.1002/art.20855.

2. Nicola PJ, Crowson CS, Maradit-Kremers H, Ballman KV, Roger VL, Jacobsen $\mathrm{SJ}$, et al. Contribution of congestive heart failure and ischemic heart disease to excess mortality in rheumatoid arthritis. Arthritis Rheum. 2006;54(1):60-7. https://doi.org/10.1002/art.21560.

3. Galderisi M. Diastolic dysfunction and diastolic heart failure: diagnostic, prognostic and therapeutic aspects. Cardiovasc Ultrasound. 2005;3(1):9. https://doi.org/10.1186/1476-7120-3-9.

4. Kosmala W, Marwick TH. Asymptomatic left ventricular diastolic dysfunction: predicting progression to symptomatic heart failure. JACC CardiovasC Imaging. 2020;13(1 Pt 2):215-27. https://doi.org/10.1016/j.jcmg.2018.10.039.

5. Deswal A. Diastolic dysfunction and diastolic heart failure: mechanisms and epidemiology. Curr Cardiol Rep. 2005;7(3):178-83. https://doi.org/10.1007/ s11886-005-0074-7.

6. van Riet EE, Hoes AW, Wagenaar KP, Limburg A, Landman MA, Rutten FH. Epidemiology of heart failure: the prevalence of heart failure and ventricular dysfunction in older adults over time. A systematic review. Eur J Heart Fail. 2016;18(3):242-52. https://doi.org/10.1002/ejhf.483.

7. Fontes-Carvalho R, Gonçalves A, Severo M, Lourenço P, Rocha Gonçalves F, Bettencourt $P$, et al. Direct, inflammation-mediated and blood-pressuremediated effects of total and abdominal adiposity on diastolic function: EPIPorto study. Int J Cardiol. 2015;191:64-70. https://doi.org/10.1016/j.ijcard.2 015.04.250.

8. Fontes-Carvalho R, Ladeiras-Lopes R, Bettencourt P, Leite-Moreira A, Azevedo A. Diastolic dysfunction in the diabetic continuum: association with insulin resistance, metabolic syndrome and type 2 diabetes. Cardiovasc Diabetol. 2015;14(1):4. https://doi.org/10.1186/s12933-014-0168-X.

9. Kane GC, Karon BL, Mahoney DW, Redfield MM, Roger VL, Burnett JC Jr, et al. Progression of left ventricular diastolic dysfunction and risk of heart failure. Jama. 2011;306(8):856-63. https://doi.org/10.1001/jama.2011.1201.

10. Liang KP, Myasoedova E, Crowson CS, Davis JM, Roger VL, Karon BL, et al. Increased prevalence of diastolic dysfunction in rheumatoid arthritis. Ann Rheum Dis. 2010;69(9):1665-70. https://doi.org/10.1136/ard.2009.124362.

11. Aslam F, Bandeali SJ, Khan NA, Alam M. Diastolic dysfunction in rheumatoid arthritis: a meta-analysis and systematic review. Arthritis Care Res (Hoboken). 2013:65(4):534-43. https://doi.org/10.1002/acr.21861.

12. Aletaha D, Neogi T, Silman AJ, Funovits J, Felson DT, Bingham CO 3rd, et al. 2010 Rheumatoid arthritis classification criteria: an American College of Rheumatology/European League Against Rheumatism collaborative initiative. Arthritis Rheum. 2010;62(9):2569-81. https://doi.org/10.1002/art.2 7584

13. Prevoo ML, Van't Hof MA, Kuper HH, Van Leeuwen MA, Van de Putte LB, Van Riel PL. Modified disease activity scores that include twenty-eight-joint counts. Development and validation in a prospective longitudinal study of patients with rheumatoid arthritis. Arthritis Rheum. 1995:38:44-8.

14. Lang RM, Bierig M, Devereux RB, Flachskampf FA, Foster E, Pellikka PA, et al. Recommendations for chamber quantification: a report from the American Society of Echocardiography's Guidelines and Standards Committee and the Chamber Quantification Writing Group, developed in conjunction with the European Association of Echocardiography, a branch of the European Society of Cardiology. J Am Soc Echocardiogr. 2005;18(12):1440-63. https:// doi.org/10.1016/j.echo.2005.10.005

15. Oh JK, Seward JB, Tajik AJ. The Echo Manual. second ed: Lippincott Williams \& Wilkins; 1999

16. Zile MR, Brutsaert DL. New concepts in diastolic dysfunction and diastolic heart failure: Part I: diagnosis, prognosis, and measurements of diastolic function. Circulation. 2002;105(11):1387-93. https://doi.org/10.1161/hc1102.1 05289.

17. Wan SH, Vogel MW, Chen HH. Pre-clinical diastolic dysfunction. J Am Coll Cardiol. 2014;63(5):407-16. https://doi.org/10.1016/j.jacc.2013.10.063.

18. Zhao Z, Wang H, Jessup JA, Lindsey SH, Chappell MC, Groban L. Role of estrogen in diastolic dysfunction. Am J Physiol Heart Circ Physiol. 2014; 306(5):H628-40. https://doi.org/10.1152/ajpheart.00859.2013. 
19. Mercea D, lanos R, Pop C, Lazar AL, Sitar-Tăut A, Orășan O, et al. The impact of obesity on left ventricular hypertrophy and diastolic function in Caucasian children. Metab Syndr Relat Disord. 2021;19(4):218-24. https://doi. org/10.1089/met.2020.0056.

20. Horio T, Miyazato J, Kamide K, Takiuchi S, Kawano Y. Influence of low highdensity lipoprotein cholesterol on left ventricular hypertrophy and diastolic function in essential hypertension. Am J Hypertens. 2003;16(11):938-44. https://doi.org/10.1016/S0895-7061(03)01015-X.

21. Ladeiras-Lopes R, Araújo M, Sampaio F, Leite-Moreira A, Fontes-Carvalho R. The impact of diastolic dysfunction as a predictor of cardiovascular events: a systematic review and meta-analysis. Rev Port Cardiol. 2019;38(11):789804. https://doi.org/10.1016/j.repc.2019.03.007.

22. Steven S, Frenis K, Oelze M, Kalinovic S, Kuntic M, Bayo Jimenez MT, et al. Vascular inflammation and oxidative stress: major triggers for cardiovascular disease. Oxid Med Cell Longev. 2019;2019:7092151-26. https://doi.org/10.11 55/2019/7092151.

23. Murray DR, Freeman GL. Proinflammatory cytokines: predictors of a failing heart? Circulation. 2003;107(11):1460-2. https://doi.org/10.1161/01.CIR. 0000060808.79274.0C.

24. Schwartz S. Rheumatoid carditis. JAMA. 1967;201(7):556-8. https://doi.org/1 0.1001/jama.1967.03130070076029.

25. Arslan S, Bozkurt E, Sari RA, Erol MK. Diastolic function abnormalities in active rheumatoid arthritis evaluation by conventional Doppler and tissue Doppler: relation with duration of disease. Clin Rheumatol. 2006;25(3):294-9. https://doi.org/10.1007/s10067-005-0014-3.

26. Di Franco M, Paradiso M, Mammarella A, Paoletti V, Labbadia G, Coppotelli $L$, et al. Diastolic function abnormalities in rheumatoid arthritis. Evaluation By echo Doppler transmitral flow and pulmonary venous flow: relation with duration of disease. Ann Rheum Dis. 2000;59(3):227-9. https://doi.org/10.113 6/ard.59.3.227.

27. Montecucco C, Gobbi G, Perlini S, Rossi S, Grandi AM, Caporali R, et al. Impaired diastolic function in active rheumatoid arthritis. Relationship with disease duration. Clin Exp Rheumatol. 1999:17(4):407-12.

\section{Publisher's Note}

Springer Nature remains neutral with regard to jurisdictional claims in published maps and institutional affiliations.

Ready to submit your research? Choose BMC and benefit from:

- fast, convenient online submission

- thorough peer review by experienced researchers in your field

- rapid publication on acceptance

- support for research data, including large and complex data types

- gold Open Access which fosters wider collaboration and increased citations

- maximum visibility for your research: over $100 \mathrm{M}$ website views per year

At $\mathrm{BMC}$, research is always in progress.

Learn more biomedcentral.com/submissions 